\title{
Retrospective Study of 20 Patients that has Treated with Pedicled Groin Flap in Reconstruction in Hand Injuries
}

\author{
Hokleang LY, ${ }^{2 *}$ Cheng Ngiep OU, ${ }^{1}$ Frédéric Lauwers, ${ }^{2}$ Chanmonyraksmey KY, ${ }^{3}$ Steven R Cohen, ${ }^{4}$ Jacques Saboye ${ }^{2}$ \\ ${ }^{1}$ Pediatric Surgery Department of National Pediatric Hospital, Phnom Penh, Cambodia \\ ${ }^{2}$ Maxillofacial Department, Purpan University Hospital, Toulouse, France \\ ${ }^{3}$ Plastic, Reconstructive Unit, Calmette Hospital, Phnom Penh, Cambodia \\ ${ }^{4}$ Plastic, Reconstruction Department, Rady children's Hospital, California, US
}

\begin{abstract}
Pedicled groin flap has long been playing an important role in reconstructive hand surgery. This flap is a reliable method for closing the defects of the soft tissue loss of the hand and is used in many clinical conditions. This study aims to evaluate the epidemiology and geographic aspects of the patients that required the treatment with pedicled groin flap and to assess the outcomes achieved by the Children's Surgical Centre to help guide the future practice. We studied of 20 patient that has treated with pedicled groin flap reconstruction of the hand injuries between 2009 and 2019 at the Children's Surgical Centre, Kien Klerng, Phnom Penh, Cambodia. In this study pedicled groin flap was used in 20 patients aged between 7 to 56 years, with a mean of 31 years or $40 \%$ of all patients. The sex ratio M/F was 1.5 which was 12 male patients (60 \%) and 08 female patients (40\%). The main cause of patient hand defects was from contracture related to burn sequelae which is $70 \%$.
\end{abstract}

Keywords: Pedicled groin flap, Hand defect, Reconstructions, Burn contracts

\section{Introduction}

The description of the McGregor's pedicled flap or pedicled groin flap by McGregor and Jackson was a milestone in the journey of reconstruction of soft tissue defects of the hand. Understanding of the axial pattern of blood supply in that flap led to further identification of flaps based on various cutaneous vessels. Subsequent introduction of microsurgical free flaps enormously extended the reconstructive capability, to an extent that the option of a pedicled flap to cover soft tissue defects in the hand was often relegated to the background. ${ }^{1}$ Free flaps have the advantage of being a single-stage procedure, involve fewer hospitals inpatient days, encourage the primary reconstruction of other injured structures, and patients do not have to go through the discomfort and the period of "attachment" to the abdomen (Figure 1). ${ }^{2}$

\section{Surgical Technique}

The pubic tubercle, anterior superior iliac spine, inguinal ligament, and femoral artery are marked. Doppler examination confirms the course of the SCIA, which runs parallel to and $2-3 \mathrm{~cm}$ below the inguinal ligament. If a SCIP flap is to be harvested, the dominant perforator of the superficial and deep branches of the SCIA system is usually located at the cross-point $3 \mathrm{~cm}$ medial to the anterior superior iliac spine along the course of the SCIA. A line is drawn two- fingerbreadths (approximately $3 \mathrm{~cm}$ ) below and parallel to the inguinal ligament. This is the line of the vascular pedicle. The superficial femoral artery is palpated in the femoral triangle.

If a pedicled flap is to be harvested, the dissection is begun on the lateral aspect and continued medially. On the lateral aspect of

\begin{tabular}{l|l} 
Quick Response Code: & *Corresponding author: Hokleang LY, Department of Maxillofacial surgery, Purpan University \\
Hospital, Toulouse, France. \\
Received: 30 July, 2021 \\
Citation: Hokleang LY, Cheng Ngiep OU, Lauwers F, Chanmonyraksmey KY, Cohen SR, et al. Ret- \\
rospective Study of 20 Patients that has Treated with Pedicled Groin Flap in Reconstruction in \\
Hand Injuries. Mod Res Plast Recon Sur. 2021;1(3):1-6. DOI: 10.53902/MRPRS.2021.01.000515
\end{tabular}


the flap, the incisions are made down to the fascia-Lata, the inguinal ligament, and the external oblique, and the dissection is carried medially superficial to these fascial structures. As the dissection pro- ceeds medially, the sartorius muscle becomes visible. Care is taken to visualize the pedicle as the dissection approaches the lateral border of the sartorius muscle (Figure 2 ). ${ }^{3}$

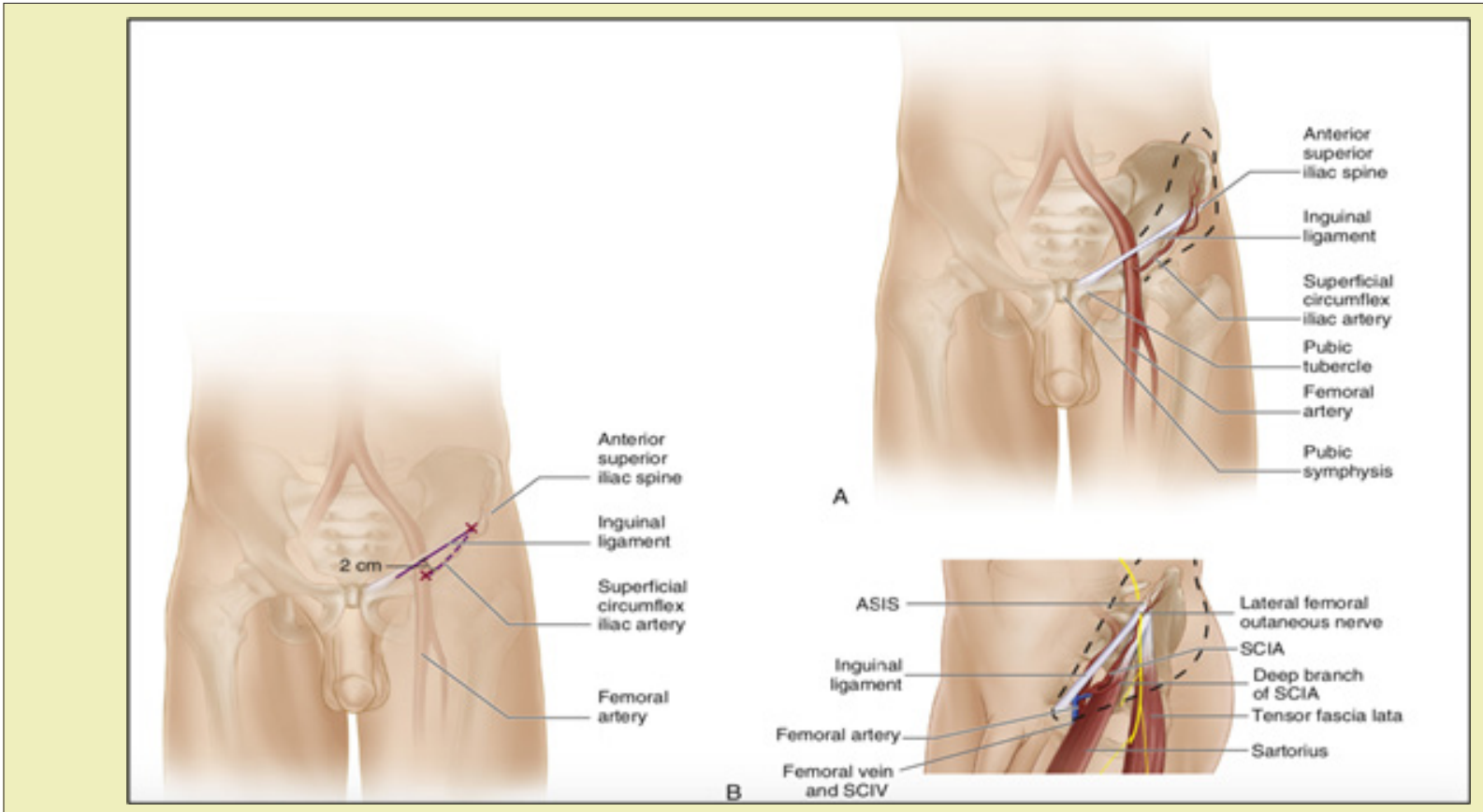

Figure 1: The anatomy of groin flap.

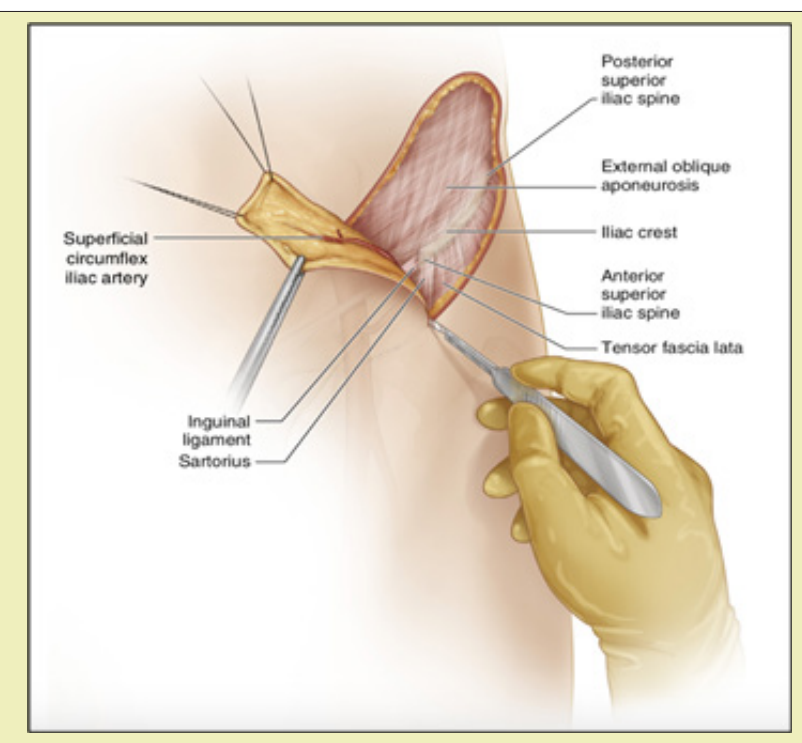

Figure 2: The procedure of dissection the pedicelled groin flap. ${ }^{3}$

\section{Material and Methods}

Despite the growing number of free and local flaps used for repairing defects of the hand, groin flaps are also still widely used. The aims of this study were to evaluate the outcomes of the patients whose hand tissue defects were covered by pedicled groin flaps after scar contracture release at Children's Surgical Center over period of 10 years (2009-2019). We discussed our study in different variables. Between January 2009 and January 2019, twenty patients with soft tissue defects of the hand and finger were reconstructed with Pedicle groin flap using the superficial circumflex iliac artery (SCIA) as the recipient vessels. The study includes twelve male and eight female patients with an average age of 31 years (range, 7-56 years). The cause of defects was noted that the burn represents 14 patients or $70 \%$, followed by crash injury 02 patients or $10 \%$, tumor 01 patient or $5 \%$, degloving injury 01 patient or $5 \%$, infection 01 patient or $5 \%$, and snake bite 01 patient or $5 \%$.

\section{Results}

The average surface of the flap was $108.55 \mathrm{~cm}^{2}$ (range, $4-12 \mathrm{~cm}$ width and $6-22 \mathrm{~cm}$ length). The average total operation time was varied between $2 \mathrm{~h}$ and $2 \mathrm{~h} 30 \mathrm{~min}$. The average duration was $2 \mathrm{~h}$ $18 \mathrm{~min}$. The mean of patient hospitalization was 34 days (Range 30120 days). In our study concerning, post-operative follow-up time of the patients with tissue loss of the hand, we noted that: Mean of follow-up time was 3 months (range 1-6 months).

\section{Follow up}

Following discharge, patients were reviewed 1 days postoperatively, and there after 1 to 3 months and 3 to 6 months' time intervals. The standard post-operative protocol include flap checked, flap examination by needle ticked and dressing. Mean of follow-up time was 3 months (Table 1).

\section{Case 1}

20-year-old women presented with burn scar contracture on both elbows and hands (Figure 3) caused by gasoline burn during her work on $5^{\text {th }}$ August 2017 in Thailand. She was treated at the 
hospital in Thailand for 2 months. On the examination she presented with:

1. Hypertrophic scar on upper back, shoulder, both arms and legs

2. Scar on the face and right ear

3. Burn scar contracture on both elbows

\section{Burn scar contracture on both hands}

After the burn scar contracture release at the right hand, we performed pedicled groin flap to cover the lesion. Pedciled division was done by 1 month after the procedure. The flap survived and healed well. Physiotherapy was performed afterward to help improve the joint and fingers functional outcomes. The patient came for follow-up 4 months after with the good result (Figure 3).

Table 1: Detailed information of patients using Pedicled groin flap for hand and finger reconstruction.

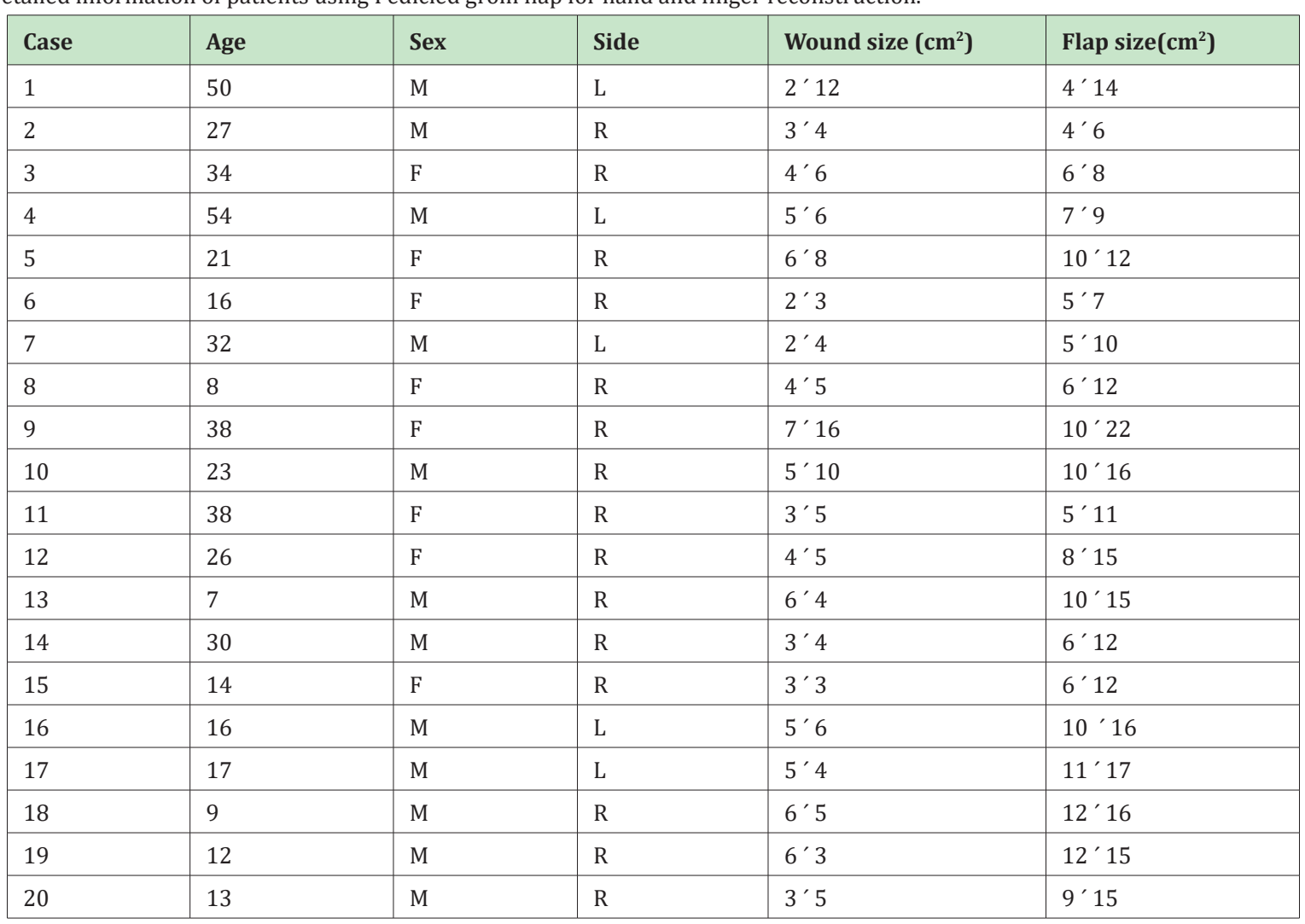

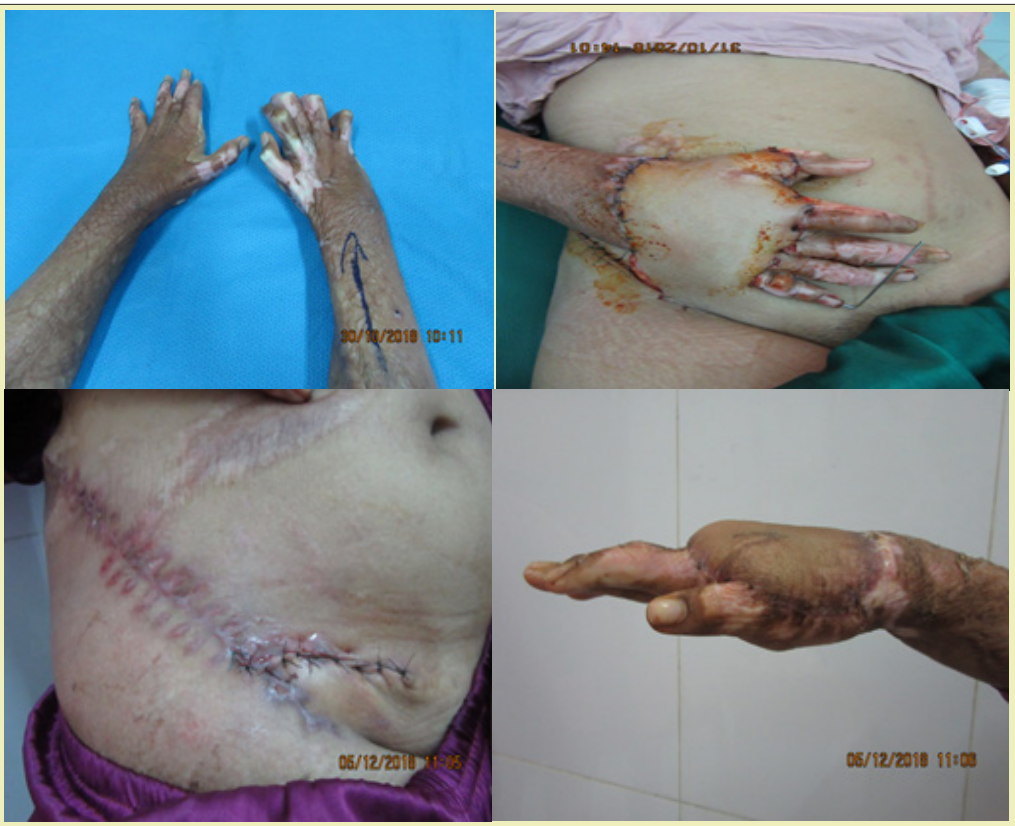

Figure 3: The success of pedicled groin flap. 


\section{Case 2}

A 21-year-old woman came from Banteay Meanchey province, presented with right wrist mass around $10 \mathrm{~cm} \times 10 \mathrm{~cm}$ from $13^{\text {th }} \mathrm{Jan}$ uary 2014 . The mass was getting bigger very quick and painful. An excisional biopsy was performed to find out the diagnostic on $2^{\text {nd }}$ April 2014. The diagnostic was giant cell tumour of distal radius. The X-ray result showed a big bone tumour of the distal radius with lytic lesion. The tumour was removed and performed the pedicled groin flap to cover the lesion on $19^{\text {th }}$ May 2014. Unfortunately, the flap was not survived because of inadequate of blood supply and infection (Figure 4). The flap was removed 2 weeks after and only kept daily dressing. Her wound was covered with fibular free flap on $29^{\text {th }}$ July 2014. The fibular flap failed because of long duration of anastomosis and venous congestion after several reprises. The flap was removed in 10 days later. At the end, she got amputation and then was operated with Krukenberg procedure on $11^{\text {th }}$ January 2015 (Figure 5).
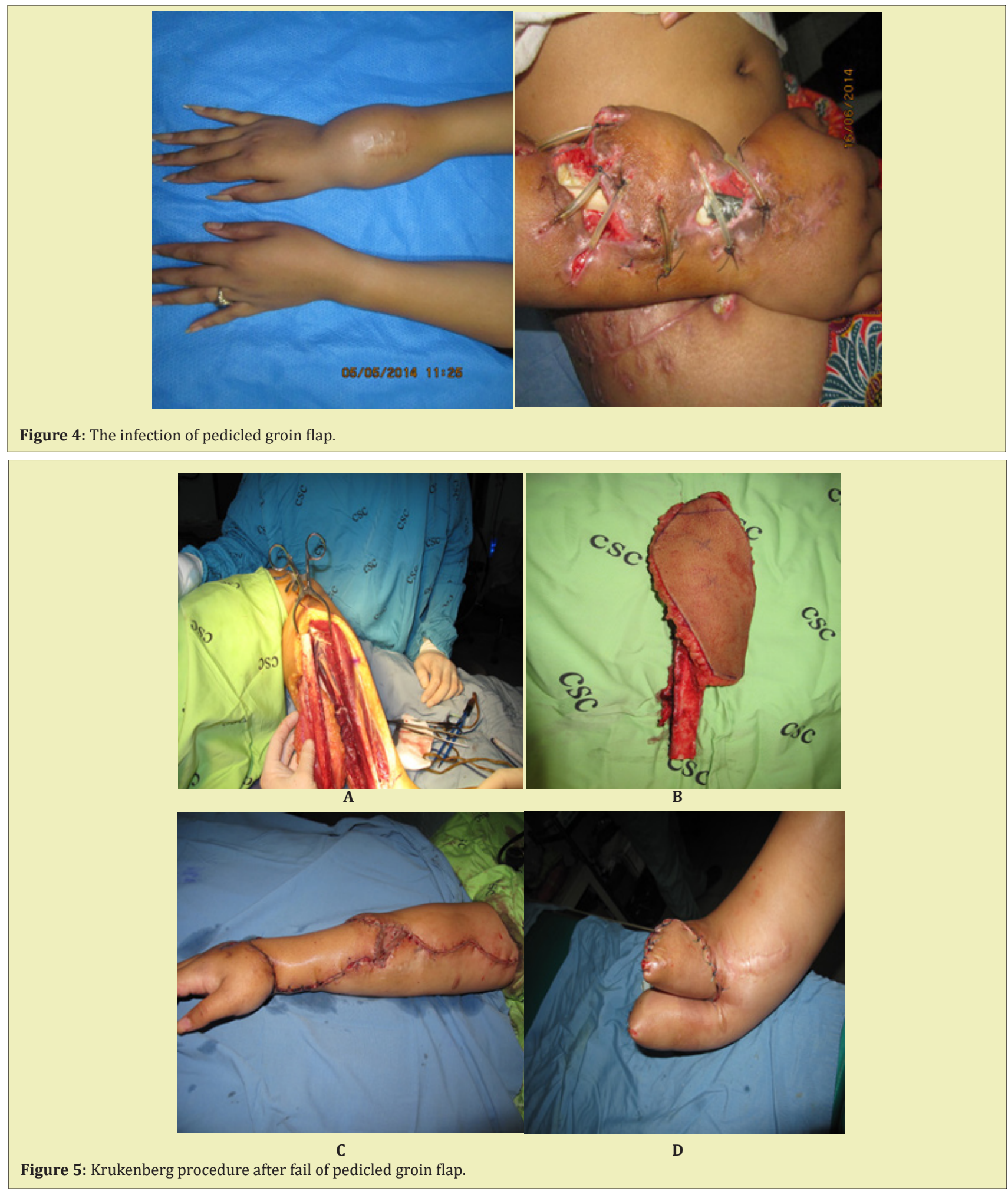


\section{Discussion}

Despite the growing number of free and local flaps used for repairing defects of the hand, groin flaps are also still widely used. The aims of this study were to evaluate the outcomes of the patients whose hand tissue defects were covered by pedicled groin flaps after scar contracture release at Children's Surgical Centre over period of 10 years (2009-2019). Many studies have investigated the result of the flap and the cause of scar contracture (Table 2).

Concerning the aetiologia, we noted that the main cause in our study is sequela of the burn that represented 14 cases or $70 \%$. It is a much higher percentage than the other studies. The various caus- es of scar contracture that required the pedicled groin flap operation from different authors were illustrated in Table 3.

Yuce $\mathrm{S}^{4}$ burn injury $45 \%$ (9 cases), machinery injury $40 \%$ (8 cases), road traffic accident $15 \%$ (3 cases). Amouzou $\mathrm{KS}^{5}$ burn injury $40 \%$ (02 cases), road traffic accident $20 \%$ (01 case), carcinoma $20 \%$ (01 case). Ghosh JC ${ }^{6}$ burn injury $17.6 \%$ (06 cases), Machinery injury $58.82 \%$ (20 cases) and road traffic accident $23.52 \%(08$ cases). Goertz $\mathrm{O}^{2}$ burn injury $12 \%$ (10 cases), machinery injury 79 $\%$ (67 cases), tumor $2 \%$ (02 cases) and infection $6 \%$ (05 cases). Our study again confirms that the result post - surgical of the flap were (Table 4$)^{7,8}$

Table 2: Comparison of patient's sex.

\begin{tabular}{|c|c|c|c|c|c|c|}
\hline Study & Country & Study period & Frequency & M & F & Sex ratio \\
\hline Yuce S $^{4}$ & Turkey & $2010-2014$ & 20 & $65 \%$ & $35 \%$ & 1.8 \\
\hline Amouzou KS $^{5}$ & Morocco & $2013-2015$ & 5 & $60 \%$ & $40 \%$ & 1.5 \\
\hline Ghosh JC $^{6}$ & Bangladesh & $2000-2001$ & 34 & $94 \%$ & $6 \%$ & 15.6 \\
\hline Goertz O & Germany & $2009-2012$ & 85 & $80 \%$ & $20 \%$ & 4.1 \\
\hline Our series & Cambodia & $2009-2019$ & 20 & $60 \%$ & $40 \%$ & 1.5 \\
\hline
\end{tabular}

Table 3: The causes of burn scar contracture.

\begin{tabular}{|c|c|c|c|c|c|c|c|}
\hline Study & Country & $\begin{array}{c}\text { Number of } \\
\text { cases }\end{array}$ & Burn & $\begin{array}{c}\text { Crash } \\
\text { injury }\end{array}$ & $\begin{array}{c}\text { Traffic } \\
\text { accident }\end{array}$ & Tumour & Other \\
\hline Yuce S & Turkey & 20 & $45 \%$ & $40 \%$ & $15 \%$ & N/A & N/A \\
\hline Amouzou KS & Morocco & 5 & $40 \%$ & N/A & $20 \%$ & $20 \%$ & $20 \%$ Ring finger \\
\hline Ghosh JC $^{5}$ & Bangladesh & 34 & $17.60 \%$ & $58.82 \%$ & $23.52 \%$ & N/A & N/A \\
\hline Goertz O & Germany & 85 & $12 \%$ & $79 \%$ & N/A & $2 \%$ & $6 \%$ Infection \\
\hline Our series & Cambodia & 20 & $70 \%$ & $10 \%$ & $5 \%$ & $5 \%$ & $\begin{array}{c}5 \% \text { infecte, } \% \\
\text { post snake bite }\end{array}$ \\
\hline
\end{tabular}

\section{Conclusion}

Hand soft tissue injuries from various causes is most common in Cambodia. It presents in soft tissue loss and hand scar contracture, which handicap the victim. The most causes of the injury were burn. The effected people were at young age. The treatment of the condition is challenging in term of covering the defect. It varies from skin graft to free vascularised predicled flap. Among these, the groin flap has an eminent role for its simple techniques, and promising result.

In our study we could see that the dimension of the hand defect between $2 \mathrm{~cm}$ to $7 \mathrm{~cm}$ in length and from $7 \mathrm{~cm}$ to $16 \mathrm{~cm}$ in width. Pedicled groin flap turned to be the first range choice of the coverage in reconstruction of the hand defects surgery. The advantages of this procedure are that it creates the proper coverage of the lesion, the improvement of daily life functional outcomes rather than the aesthetic appearance to the patients. This flap is a reliable method for closing the soft tissues defects in hand, particularly in dorsum side of the hand. The main disadvantages are the multiple procedures, long hospital stays, and the fixing of the hand to the groin region for 3 weeks or more which can cause emotional stressed. As our study we recommend that the young patient with healthy condition has the more rate of success.

\section{Acknowledgments}

The authors thanks Professor. OU Cheng Ngiep, Professor. Frédéric LAUWERS, Dr. James G Gollogly, Dr. Chanmonyraksmey KY, Dr. Jaques SABOYE and Dr. Steven R Cohen, Dr. Sam P MOST, Professor. Yong JU JANG to their cooperation in the preparation and correction of this manuscript.

\section{Funding}

None.

\section{Conflicts of Interest}

Author declares that there is no conflict of interest.

\section{References}

1. McGregor IA, Jackson IT. The groin flap. Br J Plast Surg. 1972;25(1):316.

2. Goertz O, Kapalschinski N, Daigeler A, et al. The effectiveness of pedicled groin flaps in the treatment of hand defects: results of 49 patients. J Hand Surg Am. 2012;37(10):2088-2094. 
3. Yang G, Chung KC. Pedicled and Free Groin Flap. Operative Techniques: Hand and Wrist Surgery. $3^{\text {rd }}$ ed. Elsevier BV; 2018. p. 695-702.

4. Yuce S, Oksuz M, Ersoz ME, et al. Groin flap experience in the reconstruction of soft tissue defects of the hand. Turk J Plast Surg. 2016;24:22-26.

5. Amouzou KS, Berny N, El Harti A, et al. The pedicled groin flap in resurfacing hand burn scar release and other injuries: a five-case series report and review of the literature. Ann Burns Fire Disasters. 2017;30(1):57-61.
6. Ghosh JC, Hazra SC, Singha SK, Aolad MF. Resurfacing of hand injury with groin flap: an analysis of thirty-four cases. Bangladesh Medical Journal. 2014;43(1):21-25.

7. Sabapathy SR, Bajantri B. Indications, selection, and use of distant pedicled flap for upper limb reconstruction. Hand clinics. 2014;30(2):185-199.

8. Mih AD. Pedicle flaps for coverage of the wrist and hand. Hand Clin. 1997;13(2):217-229. 